Научная статья

УДК: $581.93+502.4+502.75$

DOI: $10.18101 / 2542-0623-2021-2 / 3-56-63$

\title{
РЕДКИЕ СОСУДИСТЫЕ РАСТЕНИЯ ТУНКИНСКОГО НАЦИОНАЛЬНОГО ПАРКА
}

\author{
Д. В. Санданов \\ (C) Санданов Денис Викторович \\ кандидат биологических наук, \\ Институт общей и экспериментальной биологии СО РАН \\ Россия, 670047, г. Улан-Удэ, ул. Сахьяновой, 6 \\ Тункинский национальный парк \\ Россия, 671010, с. Кырен, ул. Ленина, 130 \\ sdenis1178@mail.ru
}

Аннотация. Подготовлена база данных локалитетов редких видов сосудистых растений на территории Тункинского национального парка. База данных функционирует в формате ГИС и включает информацию о 146 конкретных местонахождениях 51 вида. Сегодня научным отделом Тункинского национального парка ведутся работы по сохранению и воспроизводству Megadenia bardunovii на базе научного стационара в с. Кырен, также создан питомник для воспроизводства мегадении, который выполняет еще функцию поддержания резервной популяции этого редкого вида. Особую тревогу также вызывают состояние популяций и меры охраны редких растений, используемых в лекарственных целях. Это такие виды, как Rhodiola rosea, Rh. pinnatifida Boriss., Rhododendron adamsii Rehd., Caragana jubata, Fornicium carthamoides и Adonis sibirica. Для данных видов также важны подсчет и мониторинг их численности. Анализ имеющихся данных позволяет выявить распределение редких видов растений и на этой основе разработать для них меры охраны.

Ключевые слова: Бурятия, Тункинский национальный парк, редкие виды, охрана растений.

Благодарности. Автор выражает благодарность администрации Тункинского национального парка за организационную поддержку проведенных работ. Исследования частично выполнены в рамках государственного задания по теме № 121030900138-8. Автор признателен канд. биол. наук С. А. Холбоевой и канд. биол. наук И. Ю. Селютиной, принявшим участие в полевых исследованиях.

\section{Для цитирования}

Санданов Д. В. Редкие сосудистые растения Тункинского национального парка // Природа Внутренней Азии. Nature of Inner Asia. 2021. № 2-3(18). С. 56-63.

DOI: $10.18101 / 2542-0623-2021-2 / 3-56-63$

\section{Введение}

Инвентаризация флоры, выявление находок новых видов и ботаническое обследование различных ландшафтов на особо охраняемых природных территориях (ООПТ) являются важным звеном в изучении растительного разнообразия. При этом исследователи отмечают, что центры биологического разнообразия 
зачастую являются и локусами видообразования [Joppa et al., 2011; Brummit et al., 2021]. Нужно отметить, что локальные центры растительного разнообразия сохраняют определенную стабильность, а в ряде случаев характеризуются и повышением видового богатства растений [Vellend et al., 2013]. Именно в ООПТ эти показатели являются базовыми для оценки общего биологического разнообразия [Юрцев, 1992].

Флора Тункинского национального парка является богатой, но все еще недостаточно изученной. Регулярные ботанические экспедиции выявляют на территории новые виды для флоры Бурятии [Краснопевцева и др., 2009; Верхозина и др., 2013]. Для этой территории отмечается высокое разнообразие редких видов сосудистых растений, что составляет более трети всех охраняемых видов Бурятии [Красная..., 2013]. Поэтому сегодня актуальны исследования распространения, биологии и экологии редких растений Тункинского национального парка.

\section{Материалы и методы}

Все имеющиеся местонахождения были уточнены и отредактированы с использованием программ GoogleEarth и SASPlanet v91026, Global Mapper 15.1.0. Детализация координат с учетом ландшафта и типов растительных сообществ осуществлялась на основе спутниковых мультиспектральных изображений системы Landsat, для окончательной корректировки использовались топографические карты.

Разработанная база данных функционирует в формате ГИС. Для каждого вида приведены дополнительные данные по поясно-зональным и хорологическим группам согласно сводке Л. И. Малышева и Г. А. Пешковой (1984). При определении экологических групп растений частично использовались данные Т. Г. Бойкова (2005). Для некоторых видов данные по экологии уточнялись на основе данных литературы и результатов собственных исследований. Начальные сведения получены из базы данных по редким сосудистым растениям Бурятии [Санданов, 2016].

\section{Результаты}

Предварительный анализ показал, что в Красной книге Бурятии (2013) в картах ареалов для Тункинского национального парка не указаны точки распространения двух видов: Fornicium carthamoides (Willd.) R. Kam. и Nimphaea tetragona Georgi. Эта информация была дополнена, и в завершенном виде разработанная база данных включает в себя 146 конкретных местонахождений 51 редкого вида сосудистых растений (рис. 1).

Характер общего распространения редких видов сосудистых растений показал их большую представленность (изученность) в долине р. Иркут и на Тункинских гольцах, тогда как на юге территории на хребте Хамар-Дабан отмечены единичные местонахождения таких видов: Adonis sibirica Patrin ex Ledeb., Trollius lilacinus Bunge, Eutrema cordifolium Turcz. ex Ledeb., Epipogium aphyllum Sw., Lycopodium juniperoideum Sw., Cypripedium macranthon Sw.

Территория национального парка характеризуется уникальными ландшафтами и местообитаниями растений, поэтому здесь такие редкие виды, как Aconitum tanguticum (Maxim.) Stapf, Euonymus sacrosancta Koidz., Lycopodiella inundata (L.) Holub, Megadenia bardunovii Maxim., Mannagettaea hummelii Harry Sm., Oxytropis nitens Turcz., Viola alexandrowiana (W. Becker) Juz., V. ircutiana Turcz., имеют единственные местонахождения для всей территории Бурятии. 


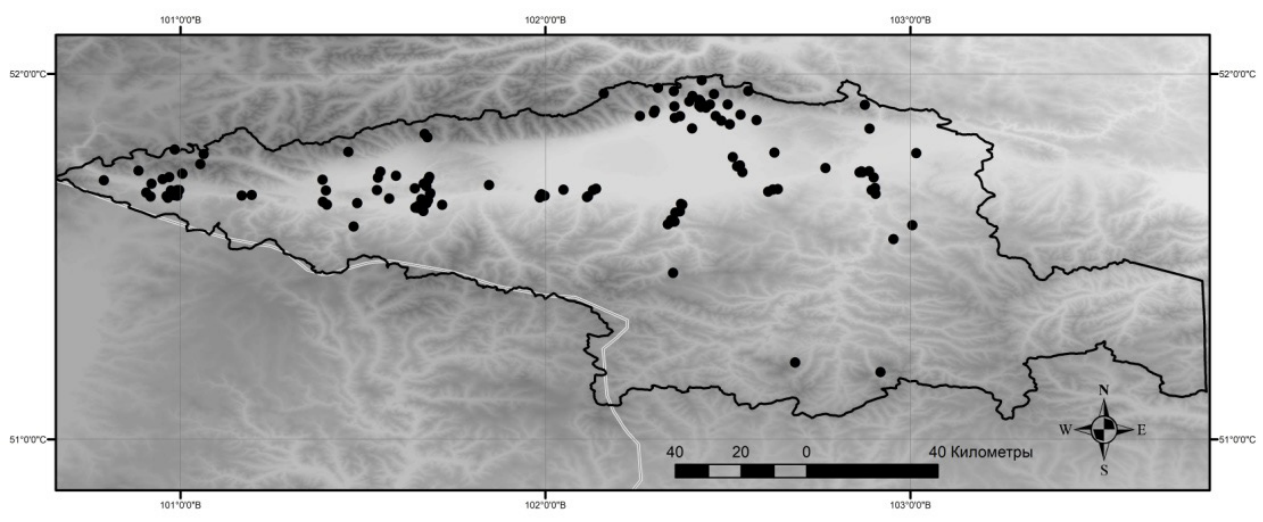

Puc. 1. Распространение редких сосудистых растений на территории Тункинского национального парка

Примечание: черной линией обозначены границы национального парка, черными точками - местонахождения видов

Основная часть ареала других редких видов (Asplenium nessi H. Christ, Cyrcaea caulescens (Kom.) Hara, Cypripedium ventricosum Sw., Eutrema cordifolium, Viola trichosepala (W. Becker) Juz.) также отмечается на территории национального парка.

Больше всего точек отмечено для Viola ircutiana (11 местонахождений), Eutrema cordifolium (9), Caragana jubata (Pall.) Poir. (9), Platanthera bifolia (L.) Rich (9).

Наиболее редким растением является Megadenia bardunovii, у которого категория статуса $1 \mathrm{a}$ - вид, находящийся под угрозой исчезновения, в критическом состоянии. Этот вид является реликтом палеогенового возраста и узколокальным эндемиком Тункинской долины. Вид долгое время считался исчезнувшим, так как единственно известная ранее популяция вида была уничтожена при строительстве дороги на Нилову Пустынь. Сегодня известно только 4 локальные популяции мегадении, все они расположены по ручьямв окрестностях с. Туран на левобережье р. Иркут: два из них находятся в ур. Дэдэ-Бори у протоки Борьский Иркут (в 7 км на запад-северо-запад от с. Туран), еще два удалены от первых на 6 км на запад-юго-запад [Макрый, Казановский, 2002].

Также очень редко встречается Aconitum tanguticum со статусом 16 - вид, находящийся под угрозой исчезновения. Данный вид встречается только в Тункинском национальном парке на Тункинских гольцах, в верховьях рек Хубыта, УлаГол, Ихе-Ухгунь, Харимта. Вне России отмечен только на северо-востоке Тибета в Китае [Красная... 2013].

К этой же категории отнесена и Mertensia sibirica (L.) G. Don fil., для которой отмечено единичное местонахождение в Тункинском национальном парке. Это эндемик Восточной Сибири, реликт плейстоценового возраста. В Бурятии вид встречается спорадически и находится около юго-восточной границы ареала.

Из других редких сосудистых растений 8 видов с 27 местонахождениями отнесены к уязвимым видам, которые сокращают численность (категория 2), a 40 видов со 111 местонахождениями входят в категорию 3 - редкий вид. Лишь один вид Lycopodiella inundata имеет неопределенный статус и отнесен к категории 4 (таблица). 
При анализе поясно-зональных групп выявлено, что большинство редких сосудистых растений относятся к светлохвойно-лесной группе (15 видов), по 6 видов входят в альпийскую, пребореальную и темнохвойно-лесную группу. В меньшей степени встречаются виды монтанной (5 видов), лесостепной (4), горно-степной (3) и водной групп (3). К водно-болотной относится лишь Mertensia sibirica, а к тундрово-высокогорной - Rhodiola rosea $\mathrm{L}$.

Состав хорологических групп показал большое число эндемичных видов (10), что отмечает разнообразие ландшафтов и геологической истории горных систем Восточного Саяна и Хамар-Дабана, условия которых способствовали формированию и сохранению эндемиков. Среди редких растений также много видов южно-сибирской (7 видов), восточно-азиатской (6), евразиатской (6) и евросибирской (5) приуроченности.

Большое число мезофитных видов (30) связано с преобладанием на территории Тункинского национального парка лесов и высокогорий. В меньшей степени отмечаются мезоксерофиты (8 видов) и растения увлажненных и переувлажненных местообитаний: гидрофиты (4), эумезофиты (2), гигромезофиты (1), мезогигрофиты (1). Редких растений засушливых местообитаний немного: Adonis sibirica, Cotoneaster neo-popovii Czer. - ксеромезофиты, Viola ircutiana, Oxytropis nitens - ксерофиты.

Последний вид характеризуется южносибирско-монгольской приуроченностью и в Бурятии находится на севере ареала. Как и другие виды секции Xerobia Bunge, встречается в Центральной Азии на степных щебнистых и каменистых склонах, степных лугах и в песчаных степях [Санданов и др., 2020].

В июне - июле 2021 г. были проведены мониторинговые исследования численности $O$. nitens в различных степных сообществах в окрестностях села Монды (таблица). На трансекте вдоль реки Булухта выявлено снижение численности Oxytropis nitens с повышением высоты на уровнем моря, что связано, во-первых, со снижением площади доступных петрофитных местообитаний для изучаемого вида, во-вторых, с уменьшением территории степных убуров. На более низких высотах вблизи села Монды число особей варьирует в зависимости от субстрата, наибольшая численность наблюдается на каменистых и щебнистых склонах.

Таблища

Численность Oxytropis nitens на степных участках в окрестностях с. Монды

\begin{tabular}{|l|l|c|c|c|c|}
\hline № & \multicolumn{1}{|c|}{ Урочище } & Широта & \multicolumn{1}{|c|}{ Долгота } & $\begin{array}{c}\text { Высота } \\
\text { над ур. м. }\end{array}$ & $\begin{array}{c}\text { Число особей, } \\
\text { шт }\end{array}$ \\
\hline 1 & река Булухта, первая терраса & 51.69579 & 100.96207 & 1488 & 1038 \\
\hline 2 & река Булухта, вторая терраса & 51.69917 & 100.96597 & 1572 & 212 \\
\hline 3 & река Булухта, третья терраса & 51.70144 & 100.96609 & 1622 & 26 \\
\hline 4 & Шара-Тала & 51.68988 & 100.90060 & 1369 & 197 \\
\hline 6 & Хулугайша & 51.68679 & 100.98335 & 1417 & 52 \\
\hline 8 & озеро Солдатское & 51.66582 & 100.97157 & 1339 & 98 \\
\hline 9 & Озеро Саринское & 51.68271 & 100.93803 & 1359 & 734 \\
\hline 10 & 1,5 км на восток от села Монды & 51.67334 & 101.02791 & 1275 & 28 на $100 \mathrm{~m}^{2}$ \\
\hline
\end{tabular}




\section{Обсуждение}

Разнообразие ландшафтов Тункинской долины с богатой растительностью способствовало сохранению большого числа редких сосудистых растений. При этом можно отметить, что флора национального парка, как и распространение редких видов растений, еще не изучена в полной мере. Определенным действием для таких исследований является разработанная в ГИС-формате база данных локалитетов, которая позволяет проводить комплексный анализ распространения редких видов сосудистых растений на изучаемой территории. Для каждого вида подобрана информация по категориям статуса, поясно-зональным, хорологическим и экологическим группам. В совокупности это позволяет оценить общую структуру и экологические предпочтения редких сосудистых растений Тункинского национального парка.

Ранее отмечалось, что функциональное зонирование национального парка не обеспечивает в должной мере сохранение редких видов растений, так как ряд их местообитаний не был охвачен охраной [Рупышев, 2009]. Новое функциональное зонирование Тункинского национального парка является более подробным, соответствует линейному типу зонирования и выстроено по долине реки Иркут [Астанин, 2018]. Сравнительный анализ распространения редких видов растений в рамках современного функционального зонирования (рис. 2) показывает неплохую охваченность охраной. Так, в особо охраняемую зону на севере ООПТ попадает много местонахождений высокогорных редких растений. Заповедная зона на юге охватывает известные местообитания видов на хребте Хамар-Дабан. Остальные точки распространения редких растений находятся в пределах подзоны массовой рекреации, рекреационной и частично в агропарковой зоне. Последняя расположена по долине Иркута в восточной части ООПТ, где не выражено разнообразие редких видов растений.

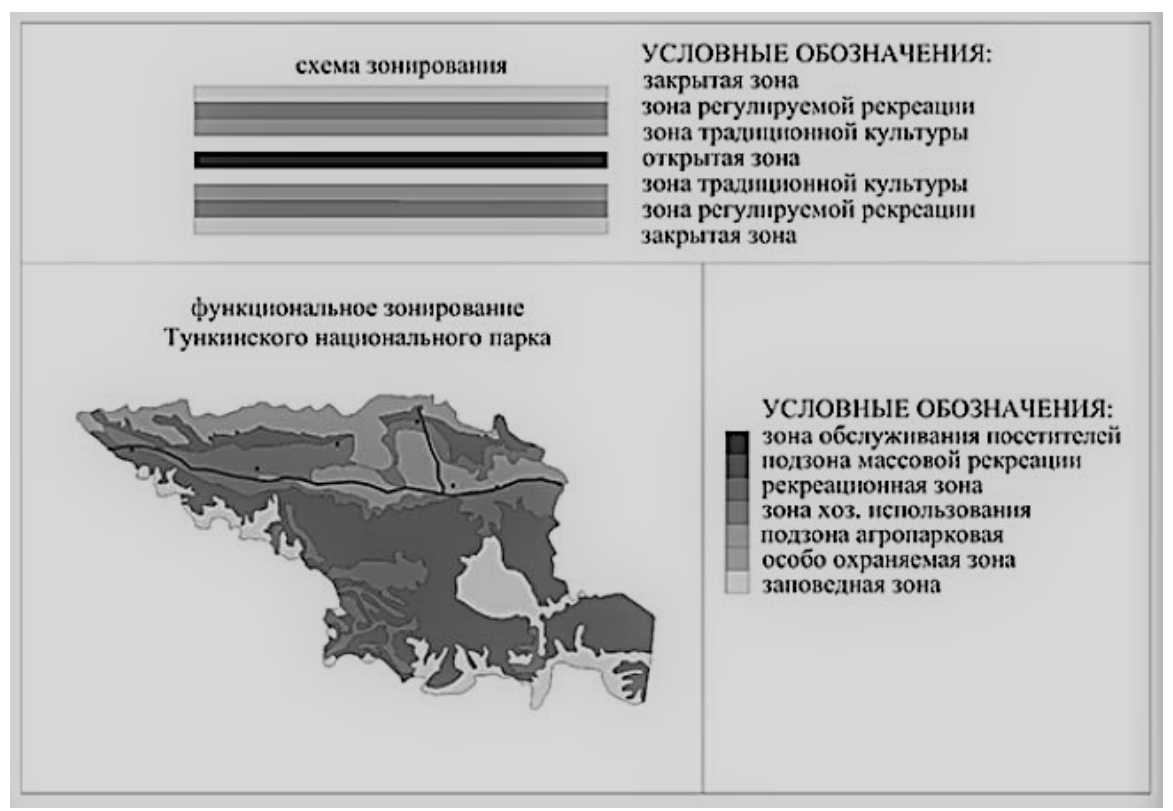

Puc. 2. Схема функционального зонирования Тункинского национального парка (по: Астанин, 2018) 
Разработанная база данных позволяет более детально оценить распространение изучаемых видов растений и разработать для них конкретные меры по их сохранению. В первую очередь необходимо обеспечить строгой охраной виды, у которых в Тункинском национальном парке отмечены единственные местонахождения для всей территории Бурятии. Например, для популяций Oxytropis nitens выявлено, что при увеличении антропогенной нагрузки наблюдается снижение жизненности и плотности популяций, неполночленность возрастного спектра, средние и низкие показатели мощности растений [Селютина и др., 2014]. Поэтому степные участки на низких высотах, прилежащие к селу Монды, необходимо охватить охраной и проводить здесь регулярный мониторинг численности и возрастной структуры вида.

Сегодня научным отделом Тункинского национального парка ведутся работы по сохранению и воспроизводству Megadenia bardunovii на базе научного стационара в с. Кырен, также создан питомник для воспроизводства мегадении, который выполняет еще функцию поддержания резервной популяции этого редкого вида.

Особую тревогу также вызывают состояние популяций и меры охраны редких растений, используемых в лекарственных целях. Это такие виды, как Rhodiola rosea, Rh. pinnatifida Boriss., Rhododendron adamsii Rehd., Caragana jubata, Fornicium carthamoides и Adonis sibirica. Для данных видов также важны подсчет и мониторинг их численности. Использование всех имеющих данных в формате ГИС и их анализ могут быть хорошей основой для проведения дальнейших природоохранных мероприятий.

\section{Литература}

1. Астанин Д. М. Типология функционального зонирования национальных и природных парков // Архитектон: известия вузов. 2018. № 61. С. 62-79. Текст : непосредственный.

2. Бойков Т. Г. Уникальные объекты растительного мира Центральной Сибири: разнообразие, пространственно-временное распределение, особенности и перспективы охраны. Новосибирск : Наука, 2005. 181 с. Текст : непосредственный.

3. Флористические находки в Республике Бурятия и Иркутской области / А. В. Верхозина, С. Г. Казановский, Н. В. Степанцова, Д. А. Кривенко // Turczaninowia, 2013. Т. 16, № 3. С. 44-52. Текст : непосредственный.

4. 4. Красная книга Республики Бурятия. Изд. 3-е. Улан-Удэ: Изд-во БНЦ СО РАН, 2013. 688 с. Текст : непосредственный.

5. Краснопевцева В. М., Краснопевцева А. С., Мартусова Е.Г. Новинки флоры сосудистых растений национального парка «Тункинский» // Turczaninowia. 2009. T. 12, № 3-4. С. 51-52. Текст : непосредственный.

6. Макрый Т. В., Казановский С. Г. Новые находки Megadenia bardunovii М. Рор. в Тункинской долине // Проблемы ботаники Южной Сибири и Монголии. Барнаул, 2002. С. 18-19. Текст : непосредственный.

7. Малышев Л. И., Пешкова Г. А. Особенности и генезис флоры Сибири (Предбайкалье и Забайкалье). Новосибирск: Наука, 1984. 264 с. Текст : непосредственный.

8. Рупышев Ю. А. Редкие виды растений Национального парка «Тункинский» новые местонахождения, состояние и перспективы охраны // Сибирский экологический журнал. 2009. № 6. С. 807-812. Текст : непосредственный.

9. Санданов Д. В. Геоинформационный анализ распространения редких сосудистых растений на территории Бурятии // Ученые записки Забайкальского государственного университета. 2016. Т. 11, № 1. С. 38-45. Текст : непосредственный. 
10. Санданов Д. В., Дугарова А. С., Селютина И. Ю. Моделирование распространения видов секции Xerobia Bunge рода Охуtropis DC. на территории Центральной Азии при климатических изменениях в прошлом и будущем // Вестник Томского государственного университета. Биология. 2020. № 52. С. 85-104. Текст : непосредственный.

11. Селютина И. Ю., Кониченко Е. С., Рупышев Ю. А. Онтогенез и онтогенетическая структура ценопопуляций редкого вида Oxytropis nitens (Fabaceae) на северной границе ареала // Ботанический журнал. 2014. Т. 99, № 9. С. 1001-1009. Текст : непосредственный.

12. Юрцев Б. А. Эколого-географическая структура биологического разнообразия и стратегия его учета и охраны // Биоразнообразие: подходы к изучению и сохранению. Санкт-Петербург, 1992. С. 7-21. Текст : непосредственный.

13. Brummit N., Araújo A. C., Harris T. Areas of plant diversity - What do we know? // Plants People Planet. 2021. Vol. 3. P. 33-44.

14. Joppa L. N., Roberts D. L., Myers N., Pimm S. L. Biodiversity hotspots house most undiscovered plant species // Proceedings of the National Academy of Science. 2011. Vol. 108, no. 32. P. 13171-13176.

15. Vellend M., Baeten L., Myers-Smith I. H., Elmendorf S. C., Beauséjour R., Brown C. D., De Frenne P., Verheyen K., and Wipf S. Global meta-analysis reveals no net change in local-scale plant biodiversity over time // Proceedings of the National Academy of Science. 2013. Vol. 110, no. 48. P. 19456-19459.

Статья поступила в редакцию 14.09.2021; одобрена после рецензирования 18.10.2021; принята к публикации 08.11.2021.

\section{RARE VASCULAR PLANTS OF TUNKINSKY NATIONAL PARK}

D. V. Sandanov

Denis V. Sandanov

Cand. Sci. (Biol.),

Institute of General and Experimental Biology SB RAS

6 Sakhyanovoy St., Ulan-Ude 670047, Russia

Tunkinsky National Park

130 Lenina St., Kyren 671010, Russia

sdenis1178@mail.ru

Abstract. The article presents a database of localities of rare vascular plants on the territory of Tunkinsky National Park. The database operates in GIS format and includes information on 146 specific locations of 51 species. Today, science department of Tunkinsky National Park is working on the preservation and reproduction of Megadenia bardunovii on the basis of a scientific station in Kyren settlement, a nursery-garden has been created for the reproduction of Megadenia, which also performs the function of maintaining the reserve population of this rare species. The state of populations and protection measures for rare plants used for medicinal purposes are also of particular concern. These are such as species Rhodiola rosea, Rh. pinnatifida Boriss., Rhododendron adamsii Rehd., Caragana jubata, Fornicium carthamoides, and Adonis sibirica. Monitoring of these species abundance is also important. Analysis of the available data makes it possible to identify the distribution of rare plant species, and to develop protection measures for them.

Keywords: Buryatia, Tunkinsky National Park, rare species, plant protection. 
Acknowledgments. We express our gratitude to the administration of Tunkinsky National Park for the assistance with the work study. The research was partly supported by a state assignment No. 121030900138-8. Our special thanks to Cand. Sci. (Biol.) S. A. Holboeva and Cand. Sci. (Biol.) I. Yu. Selyutina for participation in field research.

For citation

Sandanov D. V. Rare Vascular Plants of Tunkinsky National Park. Nature of Inner Asia. 2021; 2-3(18): 56-63 (In Russ.). DOI: 10.18101/2542-0623-2021-2/3-56-63

The article was submitted 14.09.2021; approved after reviewing 18.10.2021; accepted for publication 08.11.2021. 